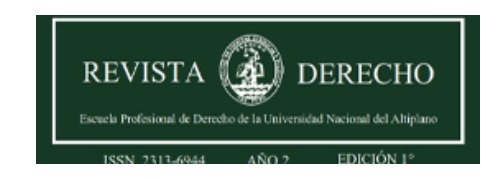

Revista de Derecho

ISSN: 2313-6944

ISSN: 2707-9651

revistaderecho@unap.edu.pe

Universidad Nacional del Altiplano

Perú

\title{
LA VÍCTIMA DEL DELITO DE TRATA DE PERSONAS, DESDE UNA ÓPTICA DEL SER HUMANO
}

Nuñez Laura, Mario Alberto

LA VÍCTIMA DEL DELITO DE TRATA DE PERSONAS, DESDE UNA ÓPTICA DEL SER HUMANO

Revista de Derecho, vol. 5, núm. 2, 2020

Universidad Nacional del Altiplano, Perú

Disponible en: https://www.redalyc.org/articulo.oa?id=671870937006

DOI: https://doi.org/10.47712/rd.2020.v5i2.95

\section{(c) (1)}

Esta obra está bajo una Licencia Creative Commons Atribución 4.0 Internacional. 


\title{
LA VÍCTIMA DEL DELITO DE TRATA DE PERSONAS, DESDE UNA ÓPTICA DEL SER HUMANO
}

\section{THE VICTIM OF THE CRIME OF HUMAN TRAFFICKING FROM A HUMAN PERSPECTIVE}

\author{
Mario Alberto Nuñez Laura \\ Coordinador Unidad de Asistencia a Victimas y Testigos del \\ Ministerio Público - Puno., Perú
}

\author{
DOI: https://doi.org/10.47712/rd.2020.v5i2.95 \\ Redalyc: https://www.redalyc.org/articulo.oa? \\ $\mathrm{id}=671870937006$
}

Recepción: 30 Septiembre 2020

Aprobación: 25 Octubre 2020

Publicación: 27 Octubre 2020

\section{RESUMEN:}

El criterio uniforme que se tiene, por parte de las personas involucradas en el ámbito jurídico, la sociedad en conjunto y de las organizaciones comprometidas en apoyar a las víctimas de los diferentes hechos de violencia o contrarios a la ley existentes en nuestro país, dentro de ellos, la víctima del delito de trata de personas es que, la consideración, trato o preocupación que se tiene por la víctima, como ser humano es deficiente, esto en el marco de la responsabilidad asistencial que tiene el Estado y la sociedad en pleno, respecto a esa persona que por mala suerte o decisiones erradas haya caído en las garras de las organizaciones de tratantes de personas, la víctima, dentro de nuestra realidad nacional, es vista solo como un número de Expediente a nivel judicial o como un número de carpeta dentro del ámbito fiscal, dejando de lado el aspecto humano, la dignidad de esa persona se desconoce o no se tiene en cuenta las necesidades, requerimientos, la situación social, familiar o económica de esa víctima, permitiendo que el desconocer de la condición en que se encuentra ese ser humano agraviado, conlleve a una falta de empatía en los servidores y personas, que de una u otra forma podrían socorrer, asistir o proteger a esa víctima.

Palabras Clave: Ser humano, víctima, trata de personas, asistencia, protección.

\begin{abstract}
:
The uniform criterion that is held, by the persons involved in the legal field, society as a whole and the organizations committed to supporting the victims of the different acts of violence or against the law existing in our country, within them, the victim of the crime of human trafficking is that the consideration, treatment or concern that is had by the victim, as a human being is deficient, this in the framework of the welfare responsibility that has the State and the society as a whole, with respect to that person who by bad luck or wrong decisions has fallen into the clutches of the organizations of traffickers in persons, The victim, within our national reality, is seen only as a file number at the judicial level or as a folder number within the fiscal sphere, leaving aside the human aspect, the dignity of that person is unknown or does not take into account the needs, requirements, social, family or economic situation of that victim, allowing the ignorance of the condition in which this human being is aggrieved, leading to a lack of empathy in the servers and people, which in one way or another could help, assist or protect that victim.
\end{abstract}

KEYWORDS: Human being, victim, human trafficking, assistance, protection.

\section{INTRODUCCIÓN}

La preocupación que se debe tener por el prójimo, es un deber de todo ser humano, bueno debería ser así, pero la realidad con la que a diario nos topamos, nos muestra una cara totalmente opuesta, desde que amanecemos, advertimos incluso dentro de algunas familias, la falta de identificación por el sentir o por los inconvenientes del otro, podemos encontrarnos con un hecho de violencia y no intervenimos, pese a ser testigos de las agresiones que está sufriendo una persona, es más, cuando somos requeridos a efectos de actuar como testigos, preferimos no involucrarnos, permitiendo con ello la posibilidad que el agresor quede impune.

Esa inhumanización a la que hacemos referencia en el párrafo precedente, la encontramos también cuando hablamos de víctimas del delito de Trata de Personas, delito que por sus características se presenta como un ilícito diferente a los demás, porque tiene como elemento la explotación humana, es un delito donde 
el agresor presenta una situación de dominio sobre un ser humano cuya singularidad es la vulnerabilidad, no considerando edad, sexo, etc., siendo aprovechado esto por el tratante para colocar a la víctima en una situación de sometimiento que le permite explotarla de formas diversas, sexual, laboral, tráfico de órganos etc., a decir de $M A Y D A R A M O S$, éstas agraviadas no son víctimas de un delito cualquiera, son seres pasivos cuya dignidad ha sido afectada. (Ramos, 2012).

Un elemento inherente a toda personas, son sus Derechos Humanos, al respecto se tiene abundante material, y específicamente a la relación de estos derechos y la trata de personas, también se cuenta con investigaciones como libros, artículos, entre otros, que nos permiten concebir una relación directa existente entre la víctima y cómo son vulnerados sus derechos fundamentales, uno de esos escritos relacionados al tema lo tenemos en el Folleto Informativo de la Naciones Unidas, que titula: "Los Derechos Humanos y la Trata de Personas", del que podemos conocer que, durante la sucesión de los hechos propios de la trata, entran en juego de forma progresiva, diversos derechos humanos, cabe mencionar que, la vulneración de estos derechos se da también de forma progresiva. (Naciones Unidas, Oficina del Alto Comisionado Derechos Humanos, 2014).

Las víctimas de trata de personas ven vulnerados sus derechos humanos en niveles diversos, tales como: sociales, económicos, políticos, civiles, culturales, familiares, considerando que dentro de los derechos humanos lesionados existe interdependencia, conllevando finalmente que el sujeto pasivo sufra una revictimización, y con ello el incremento de derechos lesionados. (Naciones Unidas - Oficina de las Naciones Unidas Contra la Droga y el delito, 2012).

Las personas por naturaleza, siempre actuamos con cuidado o con temor a que nos sucedan accidentes, así como la posibilidad de ser víctima de la delincuencia y sólo cuando ello nos ocurre, al margen del daño económico, patrimonial y hasta físico ocasionado, somos víctimas de daño psicológico, siendo éste el de mayor trascendencia negativa en nuestra persona, es el momento en que recién valoramos nuestra integridad y sobre todo nuestra dignidad, hecho similar ocurre en las víctimas de trata de personas, para ello es conveniente formar una cultura de identificación o empatía con la víctima, ponernos mentalmente en el lugar del agraviado, para de esta manera responder a la interrogante, ¿̇si a mí me hubiese sucedido ese acontecimiento negativo o traumante, como me hubiese gustado que me atiendan o asistan?, permitiendo con ello que consideremos a nuestro prójimo como uno mismo, logrando quizá que nos humanicemos más en favor de las desafortunadas víctimas.

El ser humano que es lesionado por una organización de tratantes de personas, no sólo se convierte en víctima él o ella, de forma individual, el actuar delictivo de esa organización arrastra a todo el entorno familiar, social y hasta económico de la agraviada, a convertirse en víctimas secundarias, siendo pasibles también de la indiferencia e inhumanización, respecto al trato, apoyo, asistencia y protección de los servidores de las instituciones que tienen por labor servir a estos seres, misma indiferencia y hostigamiento que reciben de vecinos, compañeros, familiares, etc., que, bajo pretexto de indagar permiten que el morbo surja entre ellos, respecto a la suerte que le ha tocado pasar a la víctima, porque en muchos casos se tiene la idea de que, si una mujer cae en las redes de los tratantes de personas, ya debe estar sirviendo a dichas organizaciones como dama de compañía o prestadora de servicios sexuales, generando el señalamiento despectivo por gran parte de la sociedad.

\section{MATERIALES Y MÉTODOS}

La presente investigación, será desarrollada tomando en cuenta el método Cualitativo, el cual nos servirá para hacer una labor de apreciación e interpretación de acontecimientos relacionados al tema de la investigación, lo que será reforzado por la presentación de algunos casos, que nos demuestren desde una óptica holística, esa carencia de empatía hacia la víctima, específicamente de trata de personas. Se hará uso de fichas de observación 
como instrumentos de apoyo. Respecto a población y muestra, por el método utilizado, no corresponde considerar una población determinada.

\section{RESULTADOS Y DISCUSIÓN}

\section{La víctima dentro del delito de trata de personas}

El tipo penal previsto en el Artículo $153^{\circ}$ del Código Penal, hace referencia a una pluralidad de medios comisivos: la violencia, la amenaza, el engaño, la coacción, el fraude, el rapto o abuso de situación de vulnerabilidad, permitiendo que erróneamente se perciba el involucramiento de la víctima, suceso que está lejos de la verdad, considerando que son justamente estos medios comisivos los que ubican a la víctima dentro de una esfera de sometimiento, donde ésta pierde todo dominio sobre la manifestación voluntaria, como derecho del ser humano, al punto de que su agresor se aventaja económicamente o consiguiendo algún otro provecho, haciendo uso de la amenaza, fuerza, el rapto, fraude, engaño, abuso de poder, u otros medios de coacción y que cuando ya no le es útil, se deshace, como de un objeto desechable, demostrando una relación de dominio del sujeto activo hacia la víctima, distinguiéndose entre el dominio expresado en el tipo penal, con el dominio existente al momento de la explotación de la víctima, siendo ésta última una modalidad de domino más intenso y traumático. (Montoya Vivanco, 2016).

El delito de Tata de Personas, a nivel mundial, es identificado como tal por la Organización de Naciones Unidas, cuando en el año 2000, en Italia, específicamente en la ciudad de Palermo, instaura el "Protocolo para prevenir, reprimir y sancionar la trata de personas, especialmente mujeres y niños”, conocido también como el "protocolo contra la trata de personas", siendo éste uno de los tres protocolos de Palermo suscritos por la convención, en ese momento, definiendo dicho Protocolo, en su artículo $3^{\circ}$, a la trata de personas de la forma siguiente: "Por "trata de personas" se entenderá la captación, el transporte, el traslado, la acogida o la recepción de personas, recurriendo a la amenaza o al uso de la fuerza u otras formas de coacción, al rapto, al fraude, al engaño, al abuso de poder o de una situación de vulnerabilidad o a la concesión o recepción de pagos o beneficios para obtener el consentimiento de una persona que tenga autoridad sobre otra, con fines de explotación..." (UNODC, 2004), el Perú ratifica su adhesión a dicho Protocolo el 23 de enero del 2002, con ello queda obligado al mismo, el cual tiene entre sus fines el de proteger y ayudar a las víctimas de trata de personas, con respeto pleno a sus derechos humanos.

Si bien es cierto, el Perú en los últimos años ha venido implementando normativamente estrategias de lucha contra la trata de personas, pero del análisis de las mismas se advierte que están hechas con un pensamiento juspositivista pleno, con un contenido frio en relación a la víctima, acogiendo quizá un criterio meramente sancionador, sin considerar la necesidad asistencial o protectora que requiere esa persona que fue vulnerada, atentando contra los bienes más preciados con que cuenta todo ser humano, como son su libertad, su dignidad, entre otros, por otro lado se tiene que, en el supuesto de haber sido rescatada de las garras de los tratantes, estos no permitirán que la víctima se desligue fácilmente de ellos, así que inicialmente buscarán entablar contacto por cualquier vía con la víctima, a efecto de convencerla de que retorne, en el caso de tener una respuesta negativa, utilizaran la violencia psicológica, con amenazas en contra de la víctima misma así como de los familiares de ésta, incluso llegando a tener contacto con éstos últimos, consiguiendo su finalidad de atemorizar a la víctima, no olvidemos que, para estas organizaciones el hecho de que la víctima este libre constituye un peligro, porque puede colaborar con la justicia, lo que significaría atentar contra la existencia de la organización así como una posible sentencia condenatoria, así que por todos los medios, y sin reparo alguno, buscarán recuperar el dominio sobre la víctima, caso contrario "eliminar" el peligro.

\section{La vulnerabilidad del ser humano víctima de trata de personas}

Dentro de los debates de séptimo Congreso de las Naciones Unidas, llevado a cabo entre el 26 de agosto al 06 de septiembre de 1985, en la ciudad de Milán - Italia, se asumió la "Declaración sobre los principios fundamentales de justicia para las víctimas de delitos y del abuso de poder", de la podemos advertir que define 
a la víctima como la persona que ha padecido daños físicos o mentales incluso económicos, en menoscabo de sus derechos fundamentales, además se tiene del citado acuerdo, que "victima" se considera también a los familiares o personas a cargo de la agraviada directa, así como también los que hayan intervenido para asistir a la víctima o prevenir el hecho de victimización, por otro lado, se considera también que el trato a las víctimas deberá ser con compasión y respeto a su dignidad, adecuando procedimientos judiciales y administrativos a sus necesidades, tomando en cuenta su opinión, e implementando medidas para minimizar las incomodidades generadas, protegiendo su intimidad y seguridad. (ACNUDH, 1985).

Es oportuno presentar un caso, con el que podremos visualizar mejor la situación por la que pasa una víctima de trata de personas: cierto día, siendo aproximadamente las 09:00 horas, recibo la llamada del fiscal de turno poniendo en conocimiento de que se había rescatado una víctima de trata, y que la misma se encontraba en la dependencia policial correspondiente, así que mi persona se constituyó junto a mi compañera de trabajo de profesión psicóloga, presentándonos ante el personal policial de servicio, indagando por las damas a quienes habían traído del operativo realizado en horas de la noche, refiriéndonos dicho personal, que desconocía de quien se trataba, pero suponía que eran las dos damas que se encontraban en el interior, y que el personal a cargo de su caso habían salido a tomas desayuno, por obvias razones omitiremos los nombres de las mismas, así que nos aproximamos a dichas señoritas, presentándonos, donde las damas nos refieren que efectivamente se trataban de las damas que habían sido intervenidas en un centro nocturno y que las habían derivado a dicha dependencia policial, pero que no sabían cuál sería suerte, es donde se presenta un hecho que realmente perturbó mi actuar, y es que una de las señoritas tenía en brazos a una criatura, que al indagar la menor y la edad de ésta, respondió que era su hija y tenía un año de nacida, así que lo primero que pregunte es, si necesitaban algo, y con una voz temerosa me dice una de ellas que tenían hambre, entonces me dirijo nuevamente al personal de guardia y pregunto si les habían dado algo de comer, refiriéndome que desconocía, en todo caso, el personal a cargo del caso debía ver por ello, por lo que, procedimos inmediatamente a comprar alimentos y proporcionárselos a las señoritas y a la bebe, mientras ingerían sus alimentos, la dama que tenía a la bebe nos comenta que estaba temerosa, y aunque no quiso decirnos su edad, por referencias se presumía que era menor de edad, bueno eso le correspondía establecer al fiscal a cargo de la investigación, y ese temor a dos aspectos, el primero es que la separen de su hija y el segundo que su pareja se moleste y la golpee, le explicamos que nuestra labor era prestarle la asistencia inmediata, hasta que retorne el fiscal y disponga la suerte de ambas, así como de la bebe, para ello mi compañera se entrevistó con la citada señorita, a efecto de poder reestablecer su estado emocional, así como fortalecerla anímicamente, estuvimos acompañando a las referidas intervenidas aproximadamente hasta el mediodía, que es cuando el Fiscal se hizo presente y dio inicio a las diligencias previstas por su Despacho, debiendo precisar que minutos antes de que se apersone el Fiscal, recién se presentó el personal policial a cargo del caso, con mi compañera sabíamos que esas diligencias tendrían una duración extensa, apoyar con el almuerzo y algo de ropa para la bebe.

Del caso podemos extraer comportamiento como el de los efectivos policiales, a cargo de las víctimas, quienes con todo derecho se preocuparon por su alimentación, pero poco o nada les importo la alimentación de las víctimas y de la bebe que, con un poco de criterio, podríamos darnos cuenta que también, a su corta edad y desconociendo que pasa a su alrededor, resulta víctima, quizá por su mala suerte de haber nacido de una víctima de trata de personas, o quizá por el hecho de no saber el futuro incierto que le espera, otro aspecto que resulta importante destacar está relacionado a las necesidades de estos seres humanos, nadie toma en cuenta que es lo que piensan o lo que quieren, considerando que estas damas no estaban detenidas, ni imputadas de delito alguno, no tenían por qué permanecer contra su voluntad en dicha sede policial, que bajo el pretexto de que se les tenía que tomar su declaración, y se estaba a la espera del Fiscal, no se les permitía abandonar el lugar, vulnerando aún más su estado, porque debemos tener en cuenta que éstas víctimas ya vienen de un estado de vulnerabilidad previo, y toda esta revictimización para satisfacer al representante del Ministerio Público o al personal policial, a quienes lo único que les importa es acopiar información y medios que sustenten su caso 
procesalmente, dejando de lado el sentir y querer de la víctima; finalmente, cuando indagamos un poco más acerca del temor que tenía la madre de la bebe, relacionado a la reacción de su pareja, pudimos conocer que era esta persona, quien la introdujo en el mundo de la prostitución, y era quien la controlaba a través de la agresión verbal y física, que la explotaba económicamente, que la había traído proveniente de otra Región y la había puesto a trabajar en el local donde fue intervenida.

Al hablar de vulnerabilidad de una víctima, resulta necesario visualizar una diversidad de situaciones, en los que se involucra factores adversos, conllevando a una dependencia, ahora bien, esta dependencia también se puede presentar de forma variada, pudiendo ser emocional, psicológica, física, social, familiar, económica, laboral, etc., a decir de Marta Gonzales - Coordinadora de Sensibilización del Proyecto Esperanza, entre la trata de personas y las masas con grado elevado de vulnerabilidad, llámese menores, personas con discapacidad, con necesidad económica, y personas refugiadas, existe una conexión, resultando importante identificar los factores preexistentes de vulnerabilidad específica a la trata, que son propios o característicos de la víctimas de ese delito. (Proyecto ESPERANZA Adoratrices, 2018).

Por otro lado se tiene, al autor Subijana Zunzunegui, quien congrega a las víctimas en dos grupos, el primero está compuesto por las víctimas comunes, las cuales no requieren una asistencia o protección especial, y por otro lado están las víctimas específicas, siendo éstas últimas las que requieren, por su situación, un atención especial de asistencia y protección, identificando dentro de estas víctimas últimas a las víctimas vulnerables, familiares, simbólicas, estatales o participantes (Zunzunegui, 2006), resultando relevantes para nuestro estudio las víctimas vulnerables y familiares, dado que ambas tienen rasgos semejantes con las víctimas de trata,

En nuestro país, la vulnerabilidad va relacionada a factores preexistentes en la víctima, como: la edad, el género, su origen o procedencia de grupos relegados, la situación emocional, carencia económica, bajo grado cultural, migración, etc., permitiendo constituirse fácilmente en botín de las organizaciones criminales, además podemos agregarle elemento favorable con que cuentan estas organizaciones y es que nuestro país se caracteriza por la informalidad existente, en casi todos los ámbitos, permitiendo ello que las víctimas sean fácilmente tentadas con ofertas laborales, económicas, de un mejor futuro, que finalmente resultan ser falsas, pero tarde es el momento que toman conciencia de su errada decisión, puesto que ya se encuentran como esclavas de la forma más aberrante de explotación.

Se tiene también otra forma de vulnerabilizar a las víctimas, específicamente en el ámbito normativo, no es muy satisfactorio para la víctima, y para comprobar ello podemos remitirnos a nuestra Constitución, como norma suprema, de la que podemos advertir la no inclusión de artículo alguno en favor específico de la víctima, si bien es cierto en su artículo primero prevé: "La defensa de la persona humana y el respeto de su dignidad son el fin supremo de la sociedad y del Estado", así como en su artículo segundo establece derechos fundamentales de las personas (Congreso Constituyente Democrático, 1993), pero del análisis de estos articulados se puede concluir que el objetivo de la norma incluye a todo sujeto o persona, cabe decir que también considera al sujeto activo de un delito, no existiendo una norma específica o que de manera taxativa salvaguarde los derechos, así como prevea la asistencia y protección de las víctimas, teniendo en consideración que éstas consideraciones normativas tendrían repercusión en seres humanos, que son tan iguales como lo son los legisladores que elaboran las normas.

\section{La actuación de las autoridades frente a una víctima de trata de personas.}

El sujeto pasivo del delito de trata de personas, en la mayoría de casos, antes de caer en las redes de las organizaciones de tratantes, ha pasado por momentos conflictivos previos, de tipo social, familiar, económico, sentimental, etc., y como producto de ello, ya se encuentra en un estado de vulnerabilidad que facilita el actuar de estas organizaciones delictivas; considero conveniente compartir un caso suscitado con una víctima, obviamente salvaguardando la identidad y demás datos, en el marco de confidencialidad y protección de la víctima, a efecto de que podamos identificar la situación real de la persona que pasa, como agraviada, por esta difícil experiencia: El caso es relacionado a una menor de 14 años, a quien para efectos de la presentación 
llamaremos Juana, la menor era extranjera, y en su país se había provenía de un hogar disfuncional, motivo por el cual Juana huye de su hogar, siendo acogida por un conocido, quien la enamora y junto a otra menor, son convencidas para viajar al Perú, llegando a la Región Puno, debo precisar que para llegar a esta región desde su país de origen, esta menor tuvo que viajar por todo el territorio peruano, puesto que el país del que provenía la menor se encuentra situado al otro extremo de donde se ubica la región de Puno, bueno aquí surge la primera interrogante: ¿Cómo hizo la menor para ingresar al país y para cruzar todo el territorio peruano, sin que las autoridades, en los diferentes controles, no hayan advertido de que quien viajaba era una menor, indocumentada, en compañía de un adulto que no era su familiar directo?, teniendo en cuenta la existencia de normatividad que contravenga dicha acción, como por ejemplo: el artículo $111^{\circ}$, párrafo tercero, y $112^{\circ}$, párrafo primero, ambos del Código de los Niños y Adolescentes[1], así como el artículo $145^{\circ}$ del Reglamento del Decreto Legislativo 1350 - Decreto Legislativo de Migraciones[2], continuando con el relato, el sujeto adulto trasladaba a la menor aduciendo que al lugar donde irían, estarían mejor y que había abundante trabajo, una vez que arribaron, el adulto se entera de que la otra menor con la que viajaban estaba con VIH, por lo que "encarga" a nuestra víctima de unos sujetos, para supuestamente retornar con la otra menor a su país de origen, los "encargados" de la menor la hacen trabajar ofreciendo servicios sexuales, hasta que gracias a un operativo de la fiscalía y la policía, logran rescatar a Juana, la menor es colocada en una Sala de Acogida que tiene el Ministerio Público, para cobijar de forma temporal a la víctimas de trata de personas, aquí consideramos una segunda interrogante: ¿̨por qué la menor tuvo que estar tanto tiempo en una Sala de Acogida, cuando la normativa vigente establece que debió ser puesta a disposición del juzgado pertinente o de la Unidad de Protección Especial - UPE, para que sea derivada a un albergue especializado, donde pueda recibir la asistencia acorde a su edad?, tomando en cuenta el estado de desprotección y/o abandono en que se encontraba la menor, para lo cual se tiene normatividad que salvaguarda a los menores, como el artículo $248^{\circ}$ incisos b), g) e i), del Código de los Niños y Adolescentes[3], seguimos con la narración, durante su estadía en la Sala de Acogida, esta víctima fue asistida por la Unidad de Asistencia Inmediata del Ministerio Público, entonces si bien tenía habitación y alimentación, además de asistencia Psicológica y Social, pero la persona por medidas de seguridad, no puede salir de dicha Sala de Acogida, entonces, como todo ser humano que se encuentra aislado, empiezan a aparecer otros requerimientos, como: exigencias propias de su género (elementos para su aliño personal femenino, ropa interior, etc.), antojos que todo ser humano tiene en determinado momento, comunicación con el mundo exterior, con algún familiar o amistad, finalmente ejercer su derechos a la libertad, tengamos en cuenta que la menor no estaba siendo imputada de delito alguno, muy por el contrario era víctima, pero sobre todo era un ser humano en ejercicio de sus derechos como tal, continuando con el caso, posteriormente la menor fue derivada al juzgado, el mismo que dispuso su internamiento en un albergue para menores, en todo ese trajín, incluida su estancia en el albergue, ya transcurrieron más de 30 días, la menor realmente estaba desesperada porque se encontraba en un país extraño, rodeada de personas desconocidas además de considerarse elemento de un sistema que desconocía y promesas incumplidas, puesto que si bien, los profesionales que tenían contacto con ella, conocían de su desesperación y hasta afectación emocional por el estado en que se encontraba, generando en el personal asistencial sentimientos de pesar por la menor, con quien se comprometían a efecto de hacer todo a su alcance para que pueda salir de esto y retornar con su familia a su país de origen, esto se dificultaba por el actuar de ciertos funcionarios, como por ejemplo, la juez a quien se planteó la autorización de salida del albergue y retorno a su país de origen, adjuntando los documentos que se tenía y los que se había logrado recabar de su país, esto al haber tenido ya contacto con sus familiares y esto, por los escasos recursos con los que contaban, sólo podían enviar los documentos de forma virtual, los mismos que fueron presentados al juzgador, quien con una actitud, al parecer, extremadamente pegada a la ley, y sin tomar en cuenta los derechos humanos y la situación de esta víctima, rechazo el pedido, observando entre otros, la originalidad de los documentos provenientes del país de origen de la menor, hecho que dilató el requerimiento, con el consiguiente perjuicio en los derechos de la menor, finalmente después de haberse involucrado y puesto en conocimiento del caso a 
un nivel superior, es que recién se logra que la menor sea trasladada a la ciudad de Lima, donde es entregada a la embajada de su país.

De lo compartido, se puede advertir, en relación al actuar de las autoridades, no solo acciones que contraviene la normativa vigente, en relación a menores, las víctimas, migrantes, entre otros, sino también podemos ver el actuar indiferente, con total falta de empatía o identificación con el ser humano que, antes, durante y después de su rescate ha padecido hechos de violencia, de agresión y vulneración a sus derechos a la libertad, dignidad, igualdad, entre otros, violencia cometida por sujetos al margen de la ley, pero también por profesionales encargados por el Estado de salvaguardar, asistir y proteger la integridad de las víctimas.

\section{La víctima como elemento procesal}

Resulta importante identificar cual es el papel de la víctima dentro de un proceso, y sobre ello se tiene información abundante, que señala a la víctima como elemento trascendental dentro del proceso, según Rivera Paz, la víctima en el ámbito procesal representa dos figuras importantes: la primera que es ser reconocida como tal, como víctima, y la segunda relacionada al aporte de la víctima en las investigaciones y el proceso en sí (Rivera, 2010), generando esta figura última que el papel de la víctima asuma un papel trascendental en el proceso, incluso podríamos afirmar que para los operadores de justicia involucrados resulta la pieza clave para que prospere o se cristalice su estrategia del caso; pero cierto también es, que la otra figura que representa la víctima se ve relegada, y hasta en oportunidades desaparece, por la falta de interés que despierta, esa misma figura, o sea, la "víctima” como tal, quizá sea porque su atención, asistencia y protección no generaran ningún logro en sus estadísticas institucionales.

En tal caso, podemos afirmar que la víctima, dentro de un proceso, es vista como elemento de prueba, que su aporte será significativo si sirve para el logro de una sentencia en contra del imputado, pero, atender sus requerimientos, forma de pensar, necesidades, finalmente el futuro de ésta víctima, no es un tema que requiera atención, entonces nos haríamos la interrogante si valió la pena rescatarla del mundo de explotación donde su voluntad no valía nada, pero contaba con un ingreso, aunque ínfimo, y además contaba con un círculo de compañeras o tratantes que de una u otra manera se preocupaban por ella, representando la figura de una familia, para llevarla o trasladarla a un mundo donde no es escuchada, sus necesidades no son atendidas, no cuenta con una oportunidad o posibilidad de ser útil, sin recursos para salir adelante o superar el trauma vivido, finalmente donde sólo significa un número de carpeta fiscal o expediente judicial.

Hemos sido testigos de la materialización de la víctima, transformándola, desde la óptica de los operadores de justicia, de ser humano a elemento procesal, priorizando su participación en el proceso, antes que la atención a sus necesidades, no importa si se alimentó, si tiene programada una audiencia o diligencia, primero debe cumplir con ésta, total después puede comer.

\section{La víctima de trata, post rescate.}

Los que estamos involucrados en la asistencia a víctimas, hemos podido ser testigos de que, cuando una víctima es rescatada o que por medios propios se ha liberado del cautiverio a que era sometida por los tratantes, y que se presenta ante una dependencia policial, ésta se convierte en centro de atención visual, más aún si se trata de una dependencia pequeña, como si la noticia de que ha llegado una víctima de trata de personas despertara su morbo, buscan ver a ese ser humano que pasó por las garras de las organizaciones de tratantes, y no específicamente para apoyarla o asistirla, sino para ver quien fue la mujer que estuvo de prostituta o el sujeto que estuvo de esclavo.

Otro aspecto a tomar en consideración, es el hecho de que, posterior a la liberación, la víctima pasa por todo un proceso, del cual ella en la mayoría de las veces desconoce el porqué, permitiendo la intervención de funcionarios de distintas entidades, llámese PNP, Fiscalía, Poder Judicial, Medicina Legal, UDAVIT, Ministerio de Justicia, MINSA, CEM, ONGs, entre otros, esto tomando en cuenta el D.S. No 005-2016IN, que aprueba el "Protocolo Intersectorial para la Prevención y Persecución del Delito y la Protección, Atención y Reintegración de Víctimas de Trata de Personas” (Diario El Peruano, 2016), y que todos estos 
servidores reiteran con las mismas interrogantes, generando la incomodidad de la víctima, más aún cuando estas preguntas están relacionadas con su vida íntima, o con los sucesos propios de su cautiverio.

La víctima, a efecto de justificar sus actividades durante su cautiverio y tranquilizar su sentimiento de culpa, llega a convencerse de que lo hacía estaba bien, y en oportunidades se ha visto, que el actuar de algunos operadores de justicia, lejos de disuadir ese pensamiento, sea de forma directa o indirecta, hacen que la víctima se convenza cada vez más, de su responsabilidad.

Otro aspecto que es visto como un maltrato, es el hecho de que, mientras a la víctima, sin el menor respeto por sus derechos humanos, se le retenga durante jornadas extensas, en una dependencia u otra de las entidades involucradas, bajo justificación de que se están realizando los trámites y papeleos propios de su proceso, sin tomar en cuenta que ese ser humano se encuentra agotado, temeroso, con incertidumbre sobre lo que esta pasando, agobiado por las dudas sobre su futuro, y con diversas necesidades, por el otro lado, a los imputados o investigados, respetando sus derechos, ya se le brindó alimentación, defensa legal, y demás garantía que nuestro marco normativo le reconoce.

Los maltratos y vulneraciones de sus derechos, por parte de funcionarios, servidores y personas de la sociedad civil, en agravio de la víctima, hacen que ésta haga comparaciones a la vida que llevaba cuando estaba cautiva o explotada, haciendo que los llamados a auxiliarla, asistirla, protegerla, y brindarle alternativas, aparezcamos como los que, comparativamente hablando, vulneramos más sus derechos frente a las organizaciones de tratantes, y si observamos desde una óptica más abierta, quizá tenga toda la razón, considerando que nosotros tenemos obligaciones legales y morales en favor de la víctima que no las cumplimos, en cambio los tratantes carecen de estos apremios y sólo buscan su satisfacción, es por ello que el sistema debería asumir responsabilidad.

La víctima, para retornar a su entorno o retomar su vida anterior a la trata, requiere de un proceso largo, que demanda de paciencia y sobre todo decisión y perseverancia, porque en el camino se topará con todo tipo de trabas, desde las personales, familiares, sociales, económicas y hasta culturales, considerando las personales, porque es una lucha interna diaria, respecto a asumir si la decisión adoptada es la buena o no; en relación a las familiares y sociales, porque no olvidemos que la gente es cruel en su crítica respecto al comportamiento de los demás, y de ello no se escapa la víctima de trata de personas, ello obviamente repercutirá en la familia, donde la comprensión será un factor de peso; otro elemento a considerar es el económico, la falta de recursos de todas maneras genera nuevamente un aspecto de vulnerabilidad en la víctima, que debilita su decisión y puede ocasionar un que recaiga en el mundo de la trata o de la prostitución, lo económico es importante atender, mediante alternativas, en favor de la víctima.

Esta víctima, al hacer un repaso de todo lo que le ha tocado vivir, concluye que su vida no tiene sentido, que a diferencia del resto de personas, ella ha sido elegida para una vida de sufrimiento, carente de felicidad y objetivos satisfactorios, concluyendo que, de continuar con vida, nada cambiaría, quedando lo mismo de lo ya vivido, por ello crece la idea de poner fin a esa vida llena de desgracias, acariciando la idea del suicidio. A ello se suma que, este tipo de víctimas llevan su sufrimiento de forma solitaria, y esto es debido a la humillación, la degradación, la cosificación del ser humano por la que pasan, por ello prefieren evitar que sus historias se hagan conocidas, evitan compartir sus experiencias incluso en su medio más cerrado, algún momento escuche: ser víctima de trata, es tener un tatuaje en el alma, el cual nadie lo puede ver, pero la víctima se topa con él a diario.

Nuestra indiferencia llega a tal punto, que no somos conscientes que, una víctima de trata, hasta antes de ser presa de las organizaciones de tratantes, era una persona tan común como cualquiera de nosotros, llevando quizá el mismo tipo de vida que el común de los jóvenes o personas mayores, quizá con algún grado de vulnerabilidad mayor, que si hubiese tenido las mismas oportunidades que nosotros tenemos, otro hubiese sido su futuro, por ello resulta claro imaginar, que si pudiéramos ver por sus ojos o pisar con sus zapatos, hablando metafóricamente, otra sería nuestra óptica del ser humano que pasó o que está viviendo la esclavitud en vida, y que la sola separación de su familia o sus seres queridos, de por sí resulta una experiencia traumante, difícil de superar. 


\section{CONCLUSIONES}

- La víctima del delito de trata de personas, resulta sui géneris en relación a las víctimas de delitos comunes, considerando que la víctima de trata pierde dominio sobre su manifestación de voluntad, durante y después del acontecimiento, distinguiéndose, entre el victimario y la víctima, una relación de sometimiento, el quebrantamiento a sus derechos humanos como ingrediente habitual, la vulnerabilidad de una víctima de trata, es un elemento con que cuentan favorablemente las organizaciones criminales, dando espacio a la autoincriminación, como medio de aliviar o pretender desvanecer el sentimiento de culpa.

- La particular mirada que debemos darle a la víctima de trata de personas, que si bien es cierto, por parte del sistema y de la sociedad, en consideración a que nos referimos a un ser humano víctima de esclavitud, explotación, vulnerabilidad, agravio de su dignidad, cosificación, por otro ser humano, y para combatir ello se requiere parar la indiferencia de los funcionarios o servidores del Estado, así como de la sociedad en pleno, siendo recomendable capacitar, humanizar y empatizar a los operadores de justicia, debiendo fiscalizar de manera frecuente su labor específica con las víctimas, de tal manera que lograremos minimizar la revictimización, incomodidad y desatención, como procedimiento frecuente; así como se genere normativa, visualizando la atención a la víctima como objetivo, de tal manera que la comparación que hace la víctima, entre la experiencia en manos de los tratantes y la experiencia que le toca vivir posterior a su liberación sea favorable al sistema y la sociedad. Finalmente, el largo camino de retorno a una vida de libertad y satisfacción, requiere como medios de viaje, la paciencia, decisión y perseverancia.

\section{BIBLIOGRAFÍA}

ACNUDH. (1985). Declaración sobre los principios fundamentales de justicia para las víctimas de delitos y del abuso de poder. Obtenido de https://www.ohchr.org/sp/professionalinterest/pages/victimsofcrimeandabuseofpower .aspx

Congreso Constituyente Democrático. (1993). Constitución Política del Perú.

Diario El Peruano. (12 de Mayo de 2016). Protocolo Intersectorial para la Prevención y Persecución del Delito y la Protección, Atención y Reintegración de Victimas de Trata de Personas. Obtenido de https://busquedas.elperuano.pe/download/url/aprueban-el-protocolo-intersectorial-para-la-prevencion-ydecreto-supremo-n005-2016-in-1379249-1

Montoya Vivanco, Y. (2016). El delito de trata de personas como delito complejo y sus dificultades en la jurisprudencia peruana.

Naciones Unidas - Oficina de las Naciones Unidas Contra la Droga y el delito. (2012). El Estado de Trata de Personas en el Perú. Obtenido de http://www2.congreso.gob.pe/sicr/cendocbib/con4_uibd.nsf/EC6198FCC44AB5E1 05257CDD0072F8E2/\$FILE/trata_PERU_Abril_2012_-_Final.pdf

Naciones Unidas, Oficina del Alto Comisionado Derechos Humanos. (2014). Los Derechos Humanos y la Trata de Personas.

Proyecto ESPERANZA Adoratrices. (23 de Octubre de 2018). Trata y Vulnerabilidad.

Ramos, M. (2012). Trata de Personas y acceso a la justicia. Sistematización del Primer Encuentro Nacional sobre Trata $y$ Tráfico de Personas, (pág. 32). Lima.

Rivera, C. (2010). Las victimas y la justicia transnacional. Obtenido de http://www.dplf.org/sites/default/files/128 5258696.pdf

UNODC. (2004). Convención de las Naciones Unidas contra la Delincuencia Organizada Transnacionanl y sus Protocolos. Obtenido de https://www.unodc.org/pdf/cld/TOCebook-s.pdf

Zunzunegui, I. J. (2006). El Principio de Protección de las Victimas en el Orden Jurídico Penal. Comares. 


\section{Notas}

[1] Artículo $111^{\circ}$.- “...En caso de que el viaje se realice dentro del país bastará la autorización de uno de los padres.”, Artículo $112^{\circ}$.- "Es competencia del juez especializado autorizar el viaje de niños o adolescentes dentro del país cuando falten ambos padres,..., para lo cual el responsable presentará los documentos justificatorios de la petición...”.

[2] Artículo $145^{\circ}$.- Protección a la niña, el niño o el adolescente en caso de sospecha de vulnerabilidad "MIGRACIONES determina el pase a control secundario a la niña, niño o adolecente y a su acompañante, de corresponder, cuando advierta o perciba indicios de estar ante una presunta falta, delito o circunstancia que atente contra la integridad de una niña, niño o adolescente".

[3] Artículo 248․ "El Juez especializado podrá declarar en estado de abandono a un niño o adolescente cuando:... b) Carezca, en forma definitiva, de las personas que conforme a la ley tienen el cuidado personal de su crianza, educación o, si los hubiera, incumplan las obligaciones o deberes correspondientes; o carecieran de las calidades morales o mentales necesarias para asegurar la correcta formación;... g) Sea explotado en cualquier forma o utilizado en actividades contrarias a la ley o a las buenas costumbres por sus padres o responsables, cuando tales actividades sean ejecutadas en su presencia; ... i) Se encuentre en total desamparo". 